\title{
EMPRESA AGROINDUSTRIAL POMALCA S. A.
}

\author{
Alfonso Gastañaduy Benel \\ PROFESOR DE MARKETING DE ESAN \\ MAGÍSTER EN ADMINISTRACIÓN DE ESAN \\ Ubaldo Lozano Gago \\ ECONOMISTA EXPERTO EN PROYECTOS DE INVERSIÓN
}

\section{Antecedentes}

Pomalca fue fundada como empresa agroindustrial en 1821 en el departamento de Lambayeque ${ }^{1}$. En 1902 se constituyó como Sociedad Agrícola Pomalca Ltda. con una extensión de 6608 hectáreas. El ingenio se modernizó durante la segunda década del siglo XX, como consecuencia del incremento de la demanda internacional del azúcar provocado por la Primera Guerra Mundial.

En 1920, la familia De La Piedra se hizo cargo de la Hacienda Pomalca bajo la razón social Viuda de la Piedra e Hijos, y en los siguientes cuarenta años fue adquiriendo sucesivamente las haciendas de Saltur y La Calera (1933); La Punta, Samán y Larán (1938); Sipán, La Concor-

1. Ubicado al norte del Perú, el departamento de Lambayeque comprende zonas de costa, sierra y ceja de selva. Su capital, Chiclayo, se encuentra en la costa, a 800 kilómetros al norte de Lima, capital del Perú. dia, El Palmo y Pampa Grande (1941); el fundo Mocce (1957) y los fundos La Ramada, San Juan, Santa Margarita, Santa Ana y Los Mangos (1961).

El 3 de octubre de 1970, al amparo de la Ley de Reforma Agraria (N. ${ }^{\circ} 17716$ ), promulgada por el gobierno revolucionario del general Juan Velasco Alvarado, el Complejo Agroindustrial Pomalca fue adjudicado a sus trabajadores. Para ello se formó la Cooperativa de Producción Pomalca Ltda., que comprendió una extensión territorial de 15819,39 hectáreas, el ingenio y las unidades de producción ganadera. La fábrica de alcohol quedó en propiedad de la Sociedad Pomalca Vda. De La Piedra e Hijos S. A.

El 1 de julio de 1996, luego de una gestión cooperativa de más de 25 años, los socios trabajadores, jubilados y herederos aprobaron, mediante referéndum, el cambio de modelo empresarial, de cooperativa a sociedad anónima, acogiéndose al 
Decreto Legislativo N. ${ }^{\circ} 802^{2}$ y demás normas complementarias.

El proceso de conversión y adecuación legal derivado del cambio de modelo se llevó a cabo hasta el 20 de marzo de 1997, cuando la empresa quedó debidamente inscrita en el Registro de Personas Jurídicas de la provincia de Chiclayo, departamento de Lambayeque, bajo la denominación de «Empresa Agroindustrial Pomalca S. A.» de accionariado difundido, lo cual consta en la ficha N. ${ }^{\circ} 781 \mathrm{del}$ Libro de Sociedades del Registro de Personas Jurídicas de Chiclayo.

El cambio de modelo empresarial significó un capital social de 247479034 soles, equivalente a 74318 028,23 dólares (en aquella oportunidad, el tipo de cambio era: 1 dólar $=3,33$ soles), y estaba distribuido en un total de 247479034 acciones, a un valor nominal de 1,00 sol cada acción. La estructura del accionariado quedó así:

La selección de los miembros representantes ante la junta general y la elección de los integrantes del directorio se realizaron, mediante junta general, los días 13 y 17 de abril de 1997, respectivamente.

\section{Descripción de la empresa}

\section{La planta}

La capacidad máxima estimada de las instalaciones de la Empresa Agroindustrial Pomalca es de 3400 toneladas de caña por día. El ingenio cuenta con una batería de 7 molinos de 3 mazas accionadas con un motor de corriente continua de velocidad variable. La zona de calderos, cuenta con 8 unidades con una capacidad total de 515 mil lbs/hora.

\section{Casa fuerza}

La planta de fuerza tiene 5 turbo-generadores con una capacidad total de 14790 kw. Funciona con el bagazo.

\section{Servicios}

Las diferentes labores se realizan en secciones separadas y son las siguientes: Fundición, Modelería, Caldería, Carpintería, Herrería, Maestranza (máquinas y herramientas) y Transportes.

\section{Ubicación}

La Empresa Agroindustrial Pomalca se

\begin{tabular}{|l|r|r|r|r|}
\hline Accionistas & Número & Capital (en soles) & Acciones & $\%$ \\
\hline Trabajadores & 4758 & 219987119 & 219987119 & 88,89 \\
Estado & 3 & 27491915 & 27491915 & 11,11 \\
Total & 4761 & 247479034 & 247479034 & 100,00 \\
\hline
\end{tabular}

2. Publicado en el diario oficial El Peruano el 13 de marzo de 1996, pág. 138101 y denominado
«Ley de Saneamiento Económico Financiero de las Empresas Agrarias Azucareras». 
encuentra ubicada en la provincia de Chiclayo, departamento de Lambayeque, en los distritos siguientes: Chongoyape, Zaña, Chiclayo, Reque, Monsefú y Lambayeque. La planta industrial y la sede institucional se encuentran en la localidad de Pomalca, en la carretera ChiclayoChongoyape-Chota, cuya altitud aproximada de 44 m.s.n.m.

\section{Superficie}

La superficie territorial de la empresa alcanza un total de 14837,88 hectáreas, sin considerar el área de 283,45 hectáreas ocupada por los centros poblados, cuyas viviendas se encuentran en proceso de adjudicación a los accionistas posesionarios.

El área agrícola clasificada como apta para el cultivo de la caña de azúcar representa el 84,21\% (12 494,89 ha) del total; las chacras ${ }^{3}$ ocupadas por terceros representan el 2,77\% (41 108 ha); las invernas ${ }^{4}$, el 2,77\% (410,08 ha); y las tierras eriazas, el 10,25\% (1 521 ha); todas ellas se encuentran distribuidas en las administraciones de Central Pomalca (53,8\%), Saltur y Sipán $(25,9 \%)$ y Pampa Grande $(20,3 \%)$.

\section{Aspectos legales}

En marzo de 1996, el Gobierno peruano promulgó el ya mencionado Decreto Legislativo $\mathrm{N} .^{\circ} 802$, por medio del cual, entre otros mecanismos, se estableció el Pro-

3. Pequeños terrenos agrícolas generalmente destinados al autoconsumo.

4. Tierras destinadas para el pastoreo de ganado, con humedales que facilitan el crecimiento de plantas silvestres y donde no se puede cultivar. grama Extraordinario de Regularización Tributaria (PERTA), dirigido a cambiar los fundamentos de la industria azucarera con el propósito de disminuir los niveles de deuda tributaria de esta industria.

Asimismo, con el objetivo de facilitar la transferencia del $51 \%$ del capital social de Pomalca a inversionistas privados, desde inicios de 1997 hasta la fecha (fines de 2003) se han dictado una serie de disposiciones legales, como la «Suspensión de Medidas Cautelares», que ha evitado los embargos de terceros por adeudos de la empresa.

\section{Proceso de transferencia de acciones}

Con el propósito de llevar a cabo el proceso de transferencia de acciones, el Estado peruano, a través del Cepri Azucareras $^{5}$, contrató al consorcio conformado por Ernst \& Young y el Banco Continental como asesor financiero en la búsqueda, selección e identificación de uno o más socios estratégicos que desearan adquirir un porcentaje mayoritario de participación accionaria en la Empresa Agroindustrial Pomalca. En noviembre de 1997, dicho consorcio culminó el estudio operativo, económico y financiero de la empresa en cuestión. Los montos de las proyecciones financieras respectivas fueron los siguientes:

5. Hoy incluido en Proinversión (Agencia de Promoción de la Inversión Privada), organismo público creado en el 2002 y responsable de la promoción estratégica, atención al inversionista y promoción de la inversión privada en proyectos y activos públicos. Su principal función es atraer la inversión privada, nacional y extranjera, requerida para fomentar el desarrollo del país. 
Proyecciones a capacidad alta (millones de US\$)

\begin{tabular}{|l|r|r|r|}
\hline Conceptos & Año 1 & Año 5 & Año 10 \\
\hline Ventas totales & 15261 & 49857 & 53300 \\
Costo de ventas & 17120 & 26962 & 29768 \\
Margen bruto & $(1859)$ & 22895 & 23532 \\
Otros ingresos & 100 & 108 & 120 \\
Gastos de administración & 5800 & 3653 & 4033 \\
Utilidad neta & $(7559)$ & 19350 & 19619 \\
\hline
\end{tabular}

Estos resultados no consideran los tributos por pagar (impuesto a la renta) ni las participaciones de los trabajadores.

Según estas proyecciones, en el décimo año la utilidad sería de 19,6 millones de dólares, mientras la utilidad acumulada a ese mismo alcanzaría un total de 137 millones de dólares.

Por otro lado, la Comisión de Venta de la Empresa Agroindustrial Pomalca elaboró las bases para la subasta internacional, con la finalidad de ofrecer en venta 126 millones de acciones, que representaban el 51\% del capital social autorizado, suscrito y pagado de la empresa. Con ello se buscaba incorporar un socio inversionista estratégico con capacidad financiera y experiencia en el manejo de ingenios azucareros que pudiera asumir los compromisos de inversión necesarios para repotenciar la fábrica y rehabilitar los campos de cultivo de caña de azúcar; todo ello con una administración que pudiera lograr niveles de producción y productividad acordes con una empresa competitiva.

Las bases contemplaban los requisitos que el postor debía cumplir, sobre todo con relación al pago de adeudos a los trabajadores y el compromiso de inversión:

1) Compromiso de pago de deudas laborales:

- Trabajadores cesados y/o jubilados a la fecha de la subasta pública.

- Trabajadores activos a la fecha de la subasta pública (remuneraciones atrasadas, vacaciones, compensación por tiempo de servicios, así como sus correspondientes intereses).

2) Compromiso de inversión.

3) Compromiso de apoyar el saneamiento físico legal de las áreas urbanas (pública y residencial).

No obstante, a comienzos de 1998 la subasta se cerró porque no hubo postores.

\section{Surge un inversionista}

En setiembre de 1998, un inversionista privado, Intercomercial Inc., tomó conocimiento de esta oportunidad y decidió evaluar si la reactivación de Pomalca sería posible. Para la elaboración del estu- 
dio técnico-económico contrató los servicios de un economista y de otros profesionales expertos en la industria del azúcar.

En el año 2000, luego de dos años de trabajo, dificultado por los constantes cambios de directorio y de gerentes, este equipo de profesionales terminó el diagnóstico de Pomalca y las proyecciones financieras correspondientes al rubro de la producción de azúcar. Asimismo, recomendó reorientar el objetivo de la empresa. Desde entonces y hasta hoy, siempre con la ayuda del equipo técnico que había contratado, Intercomercial Inc. siguió invirtiendo de sus propios recursos en la búsqueda de socios, así como en mantener actualizada la información sobre la empresa. Entretanto, el equipo técnico diseñó una estrategia de reestructuración de la empresa hacia actividades agroindustriales de exportación y presentó otra alternativa de negocio mucho más rentable que la de producir azúcar.

A la fecha (fines de 2003), este equipo de profesionales está culminando la elaboración de una estrategia de negocios que, además de producir azúcar, contempla otras actividades agroexportadoras, así como la producción de energía a partir de bagazo y otros servicios. Las nuevas alternativas agroexportadoras utilizarían solamente 2 mil hectáreas, lo que dejaría 10 mil hectáreas libres para las actividades del azúcar.

Sin embargo, Intercomercial Inc. no era el único interesado en la empresa azucarera. Paralelamente, otros potenciales inversionistas efectuaron estudios similares a los suyos en esos años, estudios que demandaron importantes capitales aportados por los propios interesados.
De este modo, a fines de 2003 y como producto de una rápida negociación con los trabajadores accionistas, la Empresa Agroindustrial Alimentaria San Juan logró adquirir parte de las acciones de trabajadores de Pomalca, con lo que ha obtenido el $56 \%$ del total de las acciones de la empresa. Aproximadamente el $18 \%$ del accionariado lo adquirió en la Bolsa de Valores; el resto lo compró directamente a los trabajadores. Fue una operación que tomó por sorpresa a todos los otros interesados en adquirir la empresa desde 1998.

\section{Estudio técnico-económico de Pomalca}

El siguiente es el informe ejecutivo del equipo de profesionales contratados por Intercomercial Inc. y entregado en el año 2000. Consta de dos grandes partes: el diagnóstico situacional y las proyecciones financieras. Cabe hacer notar que todas las cifras del informe están en valores constantes de 1999.

\subsection{Diagnóstico situacional}

El objetivo del presente trabajo es conocer y analizar la situación actual económica y financiera que presenta Pomalca, teniendo en consideración su desarrollo operativo, administrativo y financiero.

Las bases para este diagnóstico son los datos extraídos de las memorias anuales de la empresa, las visitas a las instalaciones (campo y fábrica) y oficinas administrativas de la empresa (Chiclayo), así como las entrevistas sostenidas con los miembros del directorio y personal ejecutivo.

Los estados financieros de los ejercicios 1998 y 1999 merecieron un dictamen 
favorable por parte de los auditores externos F. Iberico y Asociados; los estados financieros correspondientes al ejercicio de 1999 fueron debidamente analizados y expresados por los auditores indicados con base al ejercicio 1998; se utilizaron los Índices de Precios al por Mayor (IPM) correspondientes.

Para la conversión a dólares de los valores expresados en nuevos soles de diciembre de 1999, se utilizó el tipo de cambio de venta ( 1 dólar $=3,41$ soles).

Las conclusiones fueron las que se presentan a continuación:

\section{Activos principales}

La empresa cuenta con una extensión de tierras aptas para cultivos de 14838 hectáreas, de las cuales 12495 hectáreas se dedican al cultivo de caña de azúcar y 2000 hectáreas se destinan a otros fines u otros cultivos. Las áreas sembradas han venido disminuyendo año tras año, debido, fundamentalmente, a una inadecuada administración y a la falta de recursos financieros, como capital de trabajo; ello ha motivado que los rendimientos de producción y otros indicadores técnicos también hayan decrecido.

En los estados financieros 1998-1999, las tierras han sido revaluadas a 8 mil dólares la hectárea, precio elevado en comparación con los precios de mercado de la zona y otras zonas agroindustriales.

El ingenio se encuentra en total abandono y requiere con urgencia de un mantenimiento total. La planta de fuerza está operando al $30 \%$ de su capacidad y requiere de un mantenimiento adecuado. En to- tal, el ingenio, la planta de fuerza y el campo requieren una inversión de 18 millones de dólares.

En similar estado se encuentran las unidades de transporte. Y la empresa tampoco dispone de fondos financieros para su mantenimiento y/o repotenciación.

El sistema de irrigación comprende la construcción de canales principales y canales secundarios. La empresa posee 295 pozos, de los cuales solamente 84 están operativos.

\section{Producción}

Como se podrá apreciar, los rendimientos y los volúmenes de producción de caña han venido decreciendo año tras año, aparentemente por una inadecuada administración. Y lo mismo ha sucedido con la producción de azúcar.

\section{Participación en el mercado peruano}

En 1996, el total de azúcar comercial producida en el Perú fue elaborada por las 12 ex cooperativas agrarias azucareras, las cuales competían entre sí y cuya posición en el mercado interno se definía en función de su capacidad productiva, tanto a nivel de campo como a nivel de fábrica. Pomalca obtuvo el $10 \%$ de participación en el mercado, con lo que se colocó en el tercer lugar, después de Casa Grande (23\%) y Tumán (19\%).

Respecto a la venta de azúcar rubia para el mercado interno, la distribución por departamentos es la siguiente: Arequipa (49\%), Lambayeque (40,2\%), Cusco $(6,5 \%)$, Lima $(4,1 \%)$ y Piura $(0,2 \%)$. 
Estadística de rendimientos y producción de caña

\begin{tabular}{|l|r|r|r|}
\hline Parámetros & $\mathbf{1 9 7 2}$ & $\mathbf{1 9 7 4}$ & $\mathbf{1 9 9 6}$ \\
\hline Rendimiento (TM/ha cosechada) & 169 & 135 & 126 \\
Volumen de caña cosechada (TM) & 710137 & 901876 & 543763 \\
Área cosechada (ha cosechadas) & 4200 & 6674 & 4310 \\
Edad de corte (meses) & 19,02 & 15,23 & 17,28 \\
Sacarosa en caña (\%) & 13,50 & 12,96 & 12,64 \\
Eficiencia de caña (sacarosa/ha/año) & 14,32 & 13,80 & 11,04 \\
\hline
\end{tabular}

Estadística de rendimientos y producción de azúcar-planta

\begin{tabular}{|l|r|r|r|}
\hline Parámetros & $\mathbf{1 9 7 2}$ & $\mathbf{1 9 7 4}$ & $\mathbf{1 9 9 6}$ \\
\hline Azúcar comercial (TM/año) & 100210 & 92684 & 62049 \\
Azúcar rubia doméstica (TM/año) & 15392 & 18316 & 44752 \\
Azúcar rubia de exportación (TM/año) & 54117 & 43913 & 17297 \\
Azúcar refinada (TM/año) & 30701 & 30455 & 0 \\
\hline
\end{tabular}

\section{Mercadeo internacional de azúcar}

En cuanto a la exportación de azúcar, ese mismo año (1996) Pomalca ocupó también el tercer lugar, con $16 \%$ de participación, precedida igualmente por Casa Grande (37\%) y Tumán (31\%).

\section{Organización}

Los órganos de dirección de Pomalca son básicamente la junta de representantes; el consejo de vigilancia; el directorio; la gerencia; y las superintendencias de campo, fábrica, administración y servicios.

\section{Recursos humanos}

Al 15 de agosto de 1997, Pomalca contaba con 3045 trabajadores; dos años y medio después (31 de diciembre de 1999) éstos habían disminuido ligeramente: 3021 trabajadores. De este total, el 75\% son mayores de 46 años.

El $100 \%$ del personal obrero y empleado son accionistas de la empresa. No hay programas de capacitación y los sistemas de administración son totalmente obsoletos. Asimismo, los equipos de apoyo administrativo (computadoras, sistemas de

\begin{tabular}{|l|r|c|c|r|}
\hline Áreas & Obreros & Empleados & Eventuales & Total \\
\hline Administración & 9 & 179 & & 188 \\
Fábrica & 204 & 58 & 44 & 306 \\
Servicios & 398 & 150 & 25 & 573 \\
Campo & 1115 & 156 & 683 & 1954 \\
Total & 1726 & 543 & 752 & 3021 \\
\hline
\end{tabular}


comunicación, iluminación, etc.) son muy antiguos e inadecuados.

\section{Estados financieros}

Los estados financieros analizados han sido expresados en miles de nuevos soles de diciembre de 1999. Son básicamente el balance general (cuadro 1 del anexo) y el estado de ganancias y pérdidas (cuadro 2 del anexo).

\section{a) Balance general}

Al 31 de diciembre de 1999, la Empresa Agroindustrial Pomalca presenta la siguiente estructura financiera: te por el activo fijo, que representa el $92 \%$ del activo total. Sin embargo, hay que observar que estos activos (tierras) han sido revaluados por encima de los precios de mercado, probablemente con la finalidad de mejorar el patrimonio ante terceros.

El valor en libros de los activos fijos no expresa necesariamente el valor real de mercado de toda la infraestructura de la empresa; en todo caso, el valor real aproximado de mercado lo determina el Valor Nuevo de Reemplazo, VNR) ${ }^{6}$.

En cuanto a las cuentas del pasivo, los pasivos de Pomalca se vienen incremen-

Estructura financiera al 31-12-1999

\begin{tabular}{|lrr|}
\hline Concepto & $\begin{array}{c}\text { Monto } \\
\text { (en miles de US\$) }\end{array}$ & $\%$ \\
\hline Inversión & & \\
Inmuebles, maquinaria y equipo & 127123 & 92 \\
Capital de trabajo & 11381 & 8 \\
Total & $\mathbf{1 3 8 5 0 4}$ & $\mathbf{1 0 0}$ \\
\hline Financiamiento & & \\
Deuda & 63764 & 46 \\
Patrimonio & 74740 & 54 \\
Total & $\mathbf{1 3 8 5 0 4}$ & $\mathbf{1 0 0}$ \\
\hline
\end{tabular}

Al 31 de diciembre de 1999, el activo corriente apenas representa $8 \%$ del total de activos de la empresa, lo que equivale a una reducción de $15 \%$ con relación al año 1998. Las causas principales de este hecho son la disminución de la producción de campo y fábrica, la caída drástica de los rendimientos y la falta de financiamiento para repotenciar las operaciones comerciales.

Al 31 de diciembre de 1999, el activo no corriente está constituido mayormen- tando con el transcurso del tiempo porque la incapacidad financiera de la empresa le impide cumplir con sus obligaciones.

De acuerdo con el balance al 31 de diciembre de 1999, las deudas de la empresa ascienden a 63764 millones de dólares. De este total, el $67 \%$ corresponde a deudas de corto plazo, mientras el res-

6. El VNR fue determinado por los peritos tasadores en su oportunidad. 
tante $33 \%$ son deudas de largo plazo. Los principales acreedores son el gobierno peruano (19,9 millones de dólares), los trabajadores (29 millones de dólares) y los proveedores (14 millones de dólares).
Respecto al patrimonio, el capital social de Pomalca al 31 de diciembre está representado por 247479034 acciones (capital suscrito y pagado), cuyo valor nominal unitario es de un nuevo sol, y está compuesto como sigue:

Capital social al 31-12-1999

\begin{tabular}{|l|r|c|r|r|}
\hline Accionista & Número & Capital (en soles) & Acciones & \% \\
\hline Trabajadores & 4758 & 219987119 & 219987119 & 88,89 \\
Estado & 3 & 27491915 & 27491915 & 11,11 \\
Total & $\mathbf{4 7 6 1}$ & $\mathbf{2 4 7 4 7 9 0 3 4}$ & $\mathbf{2 4 7 4 7 9 0 3 4}$ & $\mathbf{1 0 0 , 0 0}$ \\
\hline
\end{tabular}

Al 20 de marzo de 1997, la estructura accionaria era la siguiente:

\begin{tabular}{|l|c|r|}
\hline Accionistas & Número de accionistas & \% \\
\hline Trabajadores & & \\
Activos & 2626 & 55,15 \\
Jubilados & 1557 & 32,70 \\
Fallecidos & 575 & 12,08 \\
Total trabajadores & $\mathbf{4 7 6 8}$ & $\mathbf{9 9 , 9 3}$ \\
Accionistas del Estado & 3 & 0,07 \\
Totales & $\mathbf{4 7 6 1}$ & $\mathbf{1 0 0 , 0 0}$ \\
\hline
\end{tabular}

\section{b) Resultados}

Los resultados obtenidos son negativos desde hace muchos años, debido fundamentalmente a elevados costos operativos, administrativos y financieros (ver cuadro 2 del anexo).

Se presume que la gerencia no ha intentado repotenciar la capacidad operativa del campo y de la planta porque está a la espera de un inversionista privado que muestre interés en la empresa y esté dispuesto a pagar sus deudas $(63,8$ millones de dólares) y a invertir los más de 30 millones de dólares necesarios para repotenciarla.

\subsection{Proyecciones financieras}

El objetivo fundamental del presente informe es elaborar las proyecciones financieras con el propósito de establecer si el proyecto puede generar recursos financieros, en términos de beneficios netos para la empresa, durante un horizonte de diez años.

- Se estima que Pomalca puede ser reorientada en su posicionamiento y estrategia empresarial, de modo que pueda volver a ser lo que fue.

- La gestión de Pomalca puede racionalizarse. Hay exceso de personal de 
campo y administrativo (más de 3 mil trabajadores), lo que explica la sobrecarga de costos innecesarios en una empresa de esa magnitud. Para las proyecciones efectuadas en este informe se considera el retiro de 1200 trabajadores, los que serán reubicados en otras actividades mucho más rentables, como parte de la solución integral de reactivación de la empresa.

- Se ha considerado 18 millones de dólares de nuevas inversiones para repotenciar los campos y la fábrica. El flujo de inversiones se muestra en el cuadro 5 del anexo.

- Se propone un préstamo de 20 millones de dólares para cumplir con las metas establecidas, monto que se amortizaría en un plazo de 10 años, con 3 años de gracia y a una tasa de interés anual de $11 \%$.

- Se ha planteado un servicio de la deuda durante 9 años, a fin de cumplir con las obligaciones atrasadas por 42,7 millones de dólares.

- La proyección conservadora de recuperación de Pomalca se muestra en los cuadros 3, 4, 5 y 6 del anexo.

- Los cuadros 7 y 8 del anexo presentan otros aspectos de la empresa.

\subsection{Evaluación económica financiera del proyecto}

La evaluación financiera está orientada a medir la inversión óptima del proyecto y a determinar su bondad en términos del beneficio neto que recibiría la empresa durante el horizonte de planeamiento, que es de diez años.
Para la evaluación financiera del proyecto se han utilizado los resultados del flujo de caja expresado en dólares y una tasa de descuento de $15 \%$ anual. Los indicadores de rentabilidad han sido los siguientes:

$$
\begin{aligned}
\text { VAN } & =\text { US\$32451000 } \\
\text { TIRe } & =55 \% \\
\text { VANf } & =\text { US\$ 15451000 } \\
\text { TIRf } & =345 \%
\end{aligned}
$$

\section{Preguntas para orientar la discusión}

- ¿Qué opina usted de las proyecciones del estudio operativo económico y financiero de Pomalca realizado por el consorcio Ernest \& Young y Banco Continental? Enfatice en su análisis los aspectos de ventas que dan sustento a las proyecciones financieras. Puede consultar en Internet la dinámica y estadísticas (comportamiento) del mercado mundial del azúcar.

- ¿Qué comentarios le merecen la nueva estrategia de diversificación que está planteando el equipo de expertos contratado por Intercomercial Inc.?

- Además de los aspectos mencionados en el estudio técnico-económico, ¿qué otros aspectos podría plantear usted?

- ¿Qué estrategias presentaría usted para reactivar la empresa?

- ¿Cuáles serían según usted las estrategias de mercadeo?

- ¿Cuáles serían las estrategias frente a los competidores locales? 
Empresa Agroindustrial Pomalca S. A.

Anexo al estudio técnico-económico 


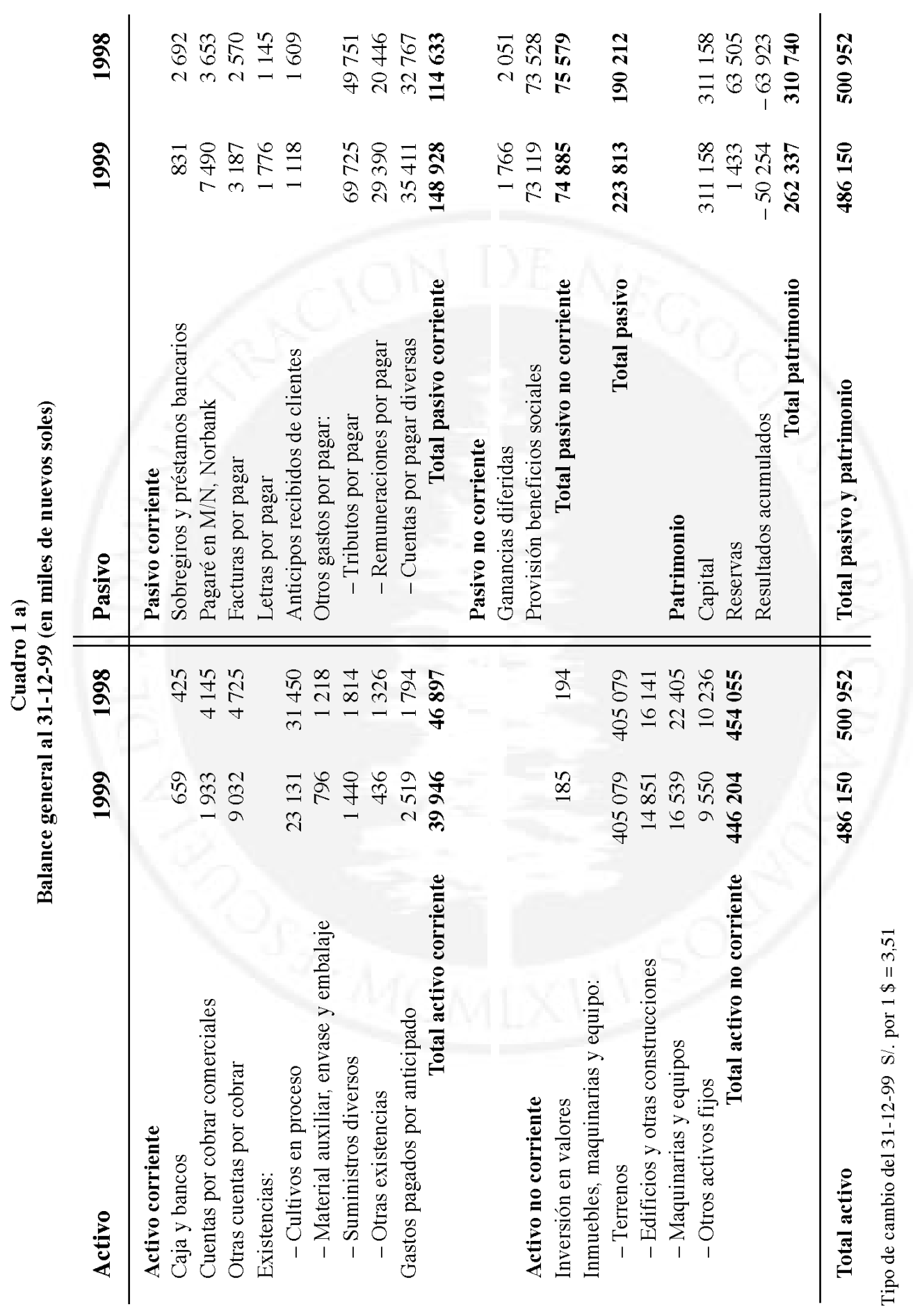




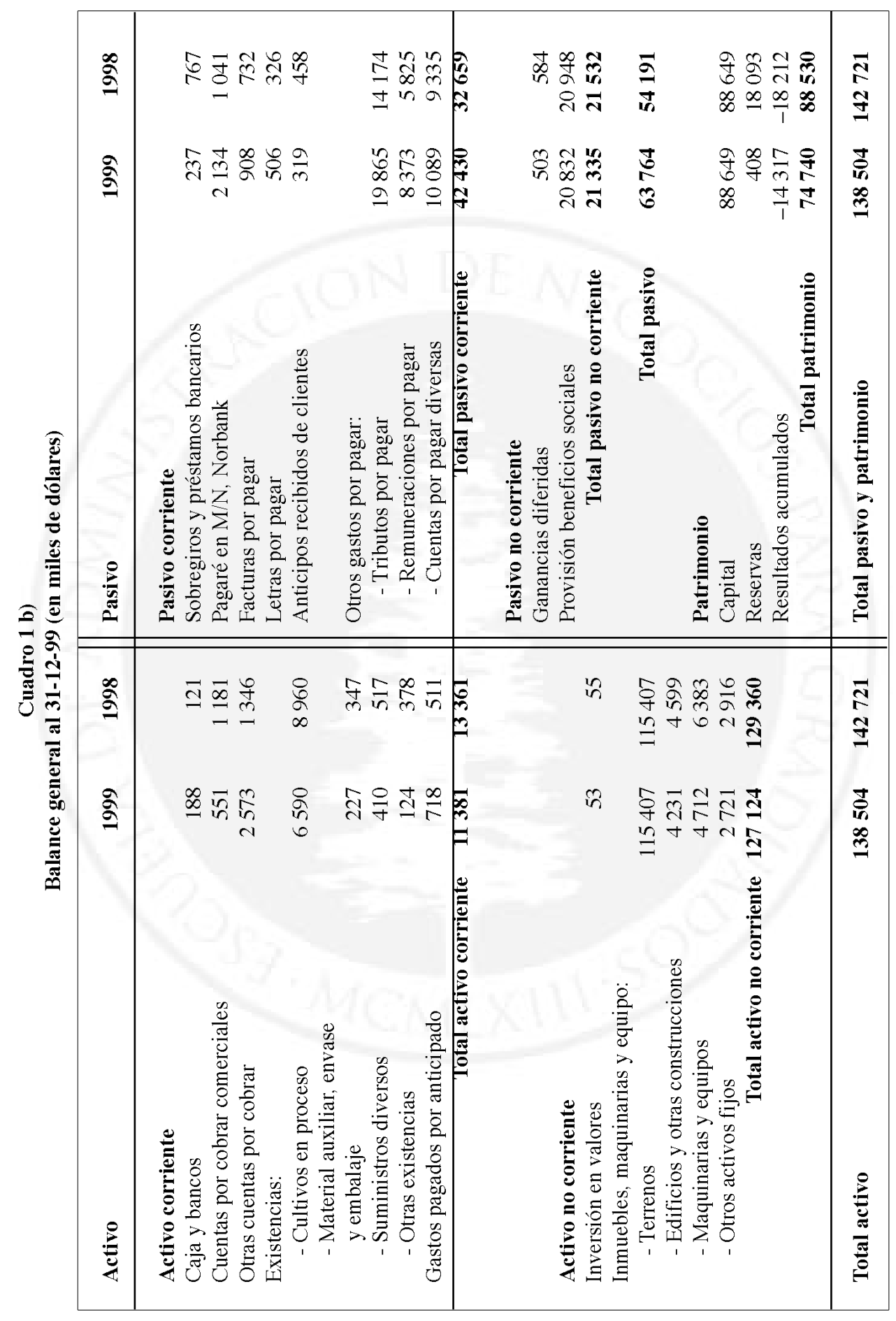


Cuadro 2 a)

Estado de ganancias y pérdidas al 31-12-99

(en miles de nuevos soles)

\begin{tabular}{|c|c|c|}
\hline Conceptos & 1999 & 1998 \\
\hline $\begin{array}{l}\text { Ingresos } \\
\text { Ventas netas } \\
\end{array}$ & $\begin{array}{l}28476 \\
28476\end{array}$ & $\begin{array}{l}28959 \\
\mathbf{2 8} 959\end{array}$ \\
\hline Costo de ventas & $\begin{array}{r}-48511 \\
\mathbf{- 2 0} 035\end{array}$ & $\begin{array}{l}-52092 \\
-\mathbf{2 3} 133\end{array}$ \\
\hline $\begin{array}{l}\text { Gastos administrativos y de ventas } \\
\text { Resultado de operación }\end{array}$ & $\begin{array}{l}-20355 \\
-40390\end{array}$ & $\begin{array}{l}-19238 \\
\mathbf{- 4 2} 371\end{array}$ \\
\hline $\begin{array}{l}\text { Otros ingresos (egresos) } \\
\text { Ingresos financieros } \\
\text { Otros ingresos } \\
\text { Gastos financieros } \\
\text { Otros egresos } \\
\text { Resultados por exposición a la inflación }\end{array}$ & $\begin{array}{r}844 \\
770 \\
-17377 \\
-2009 \\
9758\end{array}$ & $\begin{array}{r}1045 \\
1419 \\
-17519 \\
-16956 \\
10752\end{array}$ \\
\hline Utilidad neta & -48404 & -63630 \\
\hline
\end{tabular}

Tipo de cambio del 31-12-99 S/. por $1 \$=3,51$

Cuadro 2 b)

Estado de ganancias y pérdidas al 31-12-99

(en miles de dólares)

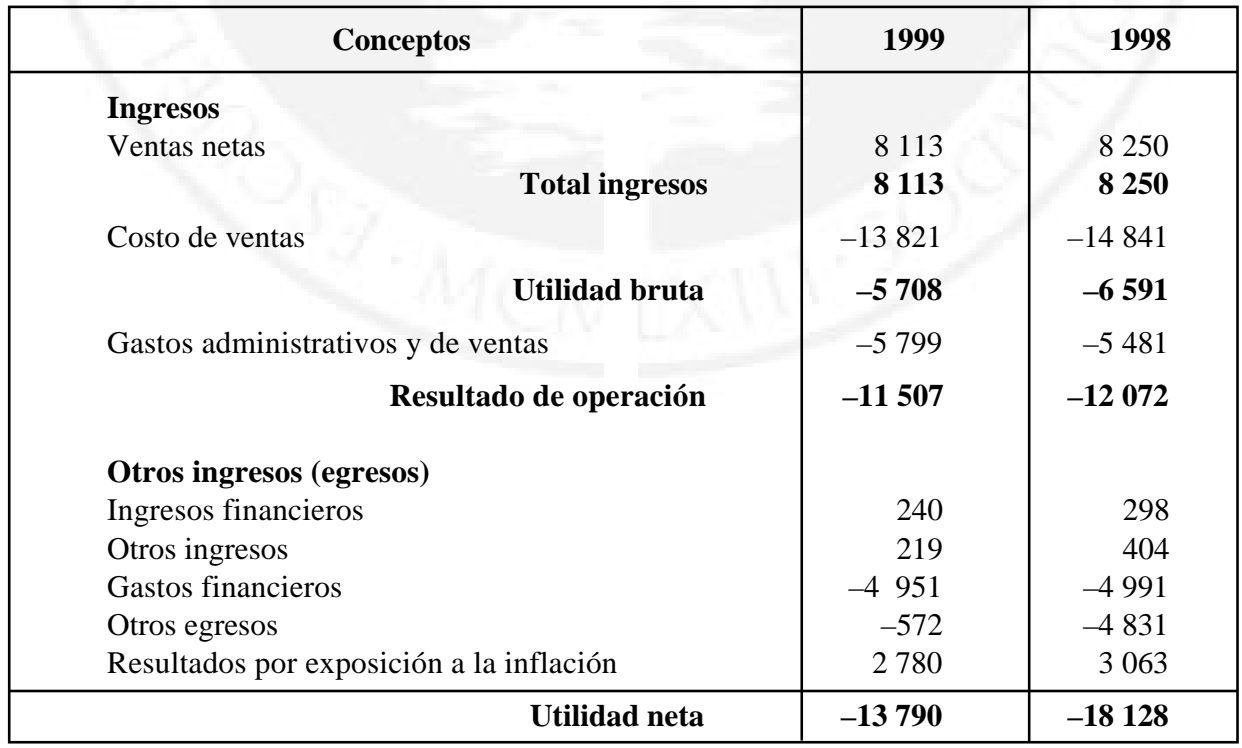




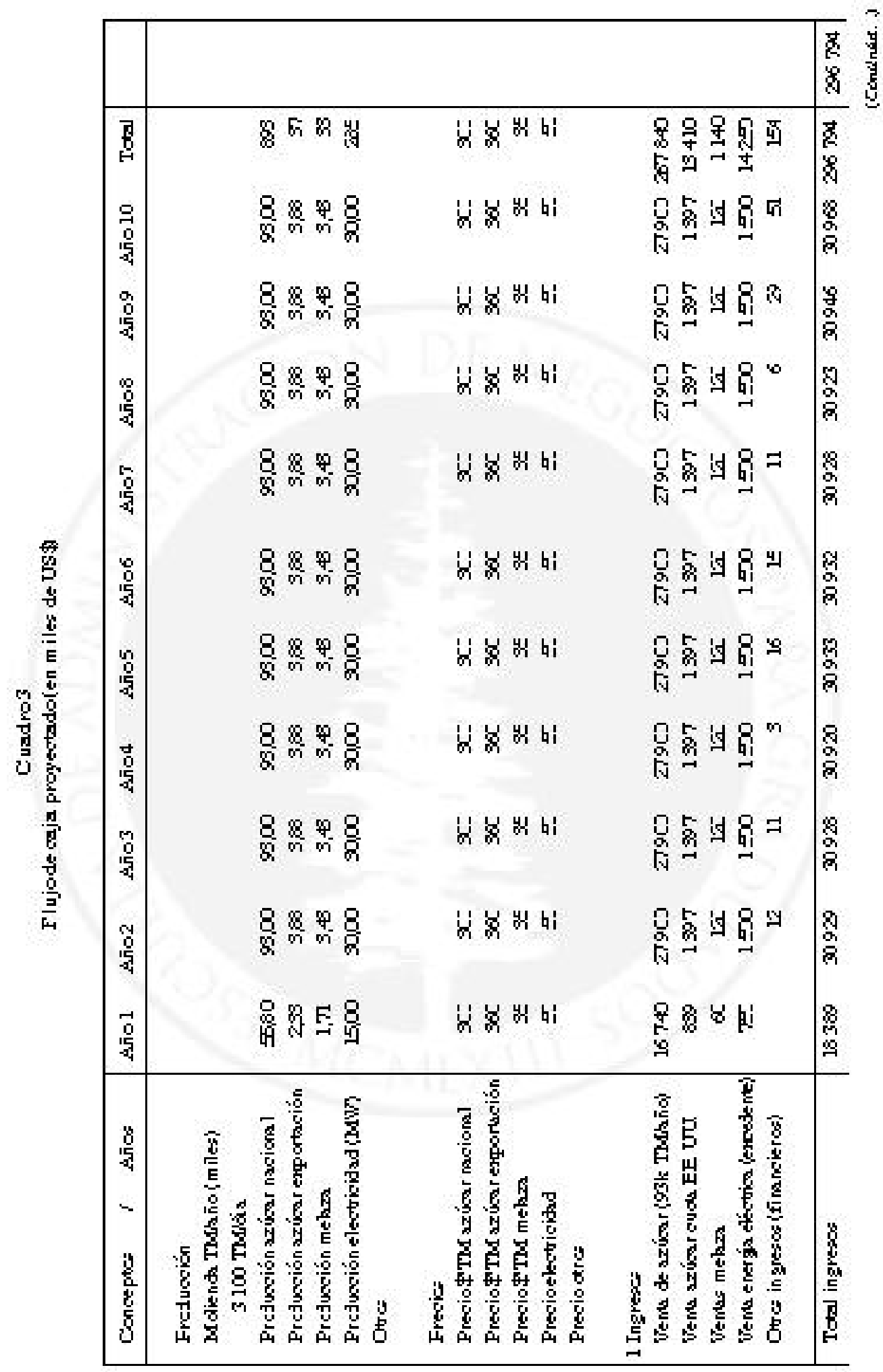




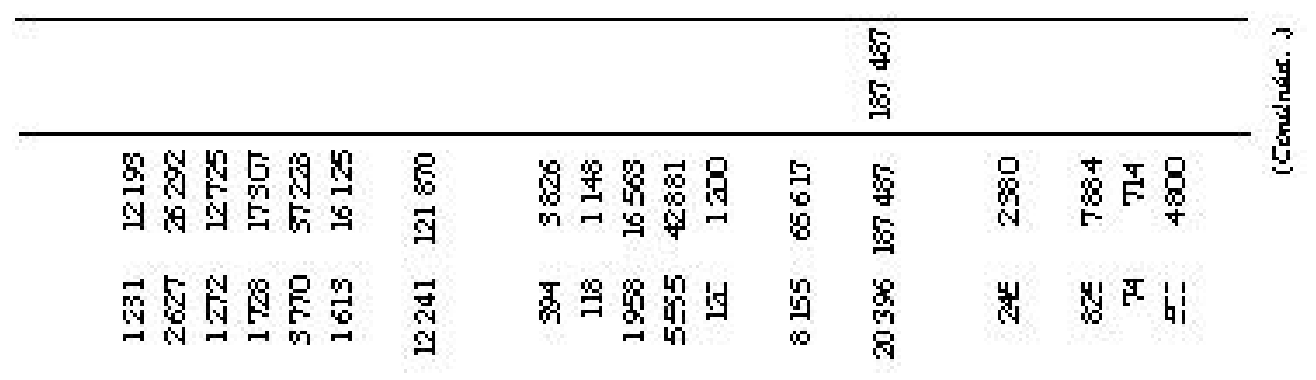

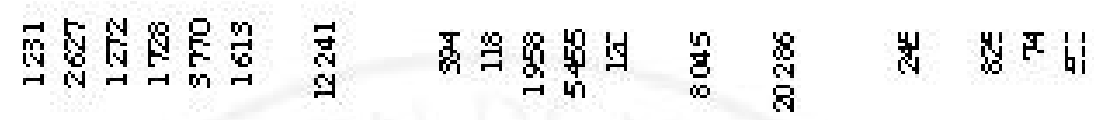

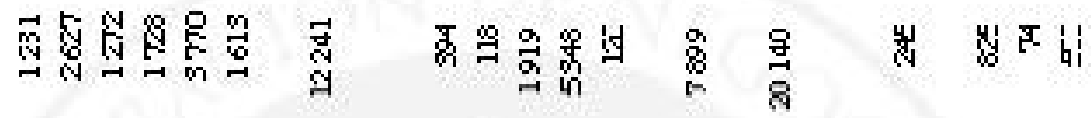

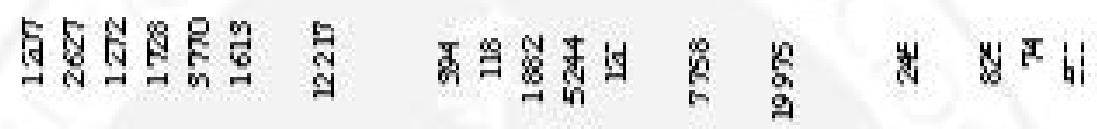

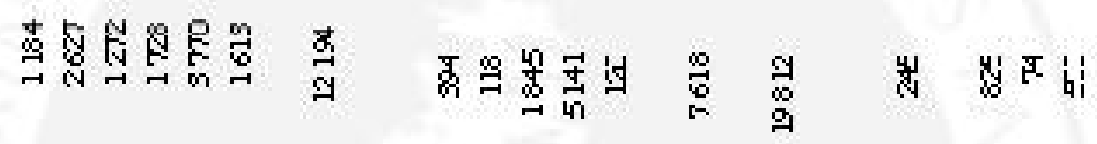

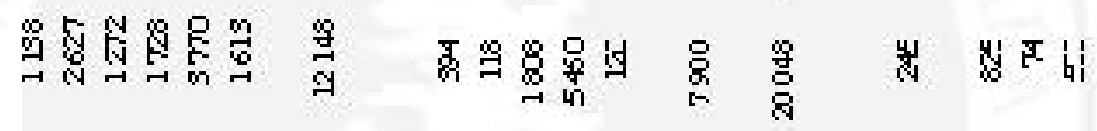

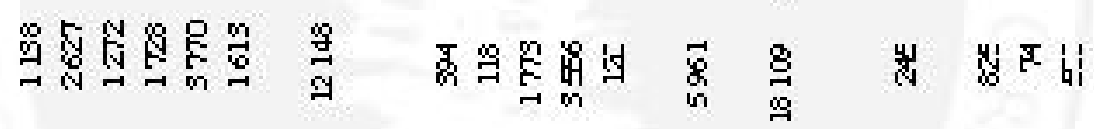

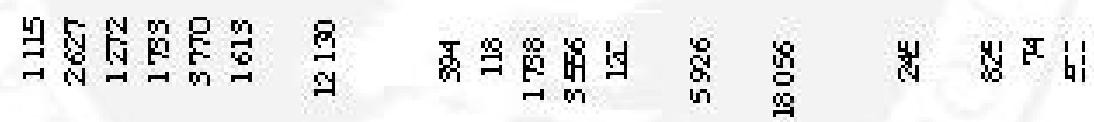

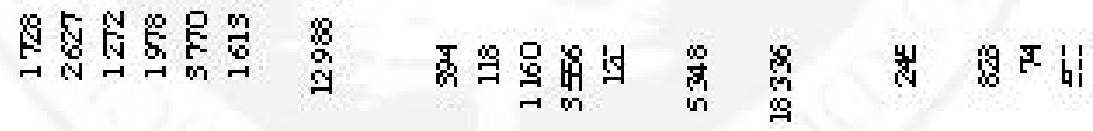

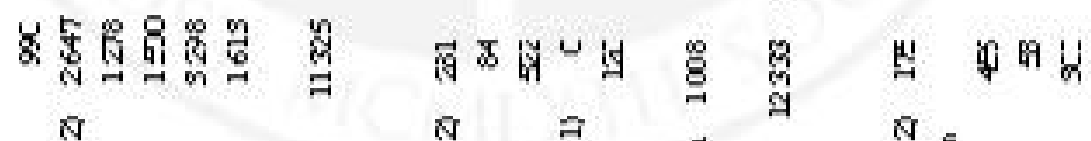

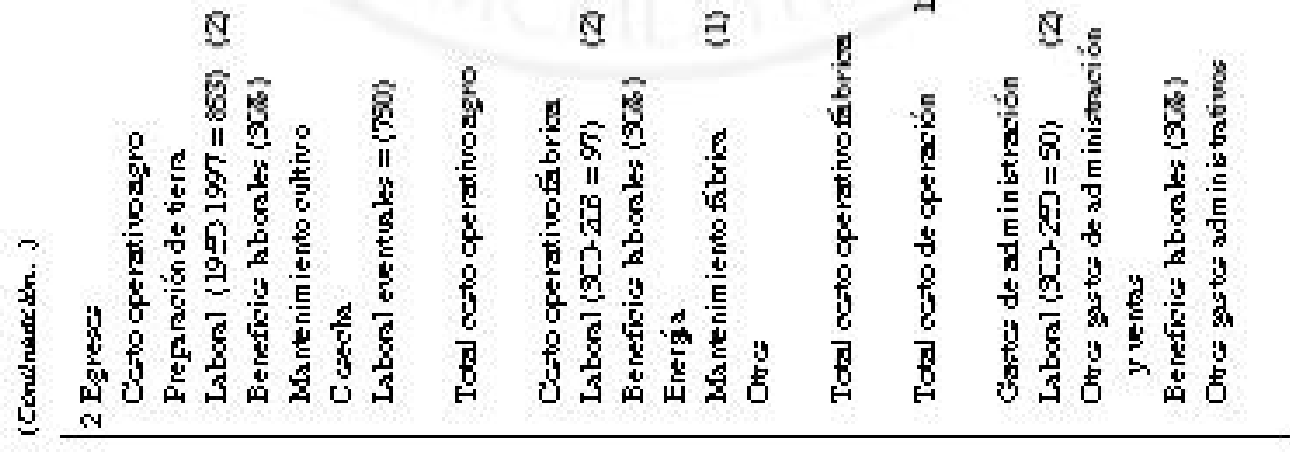




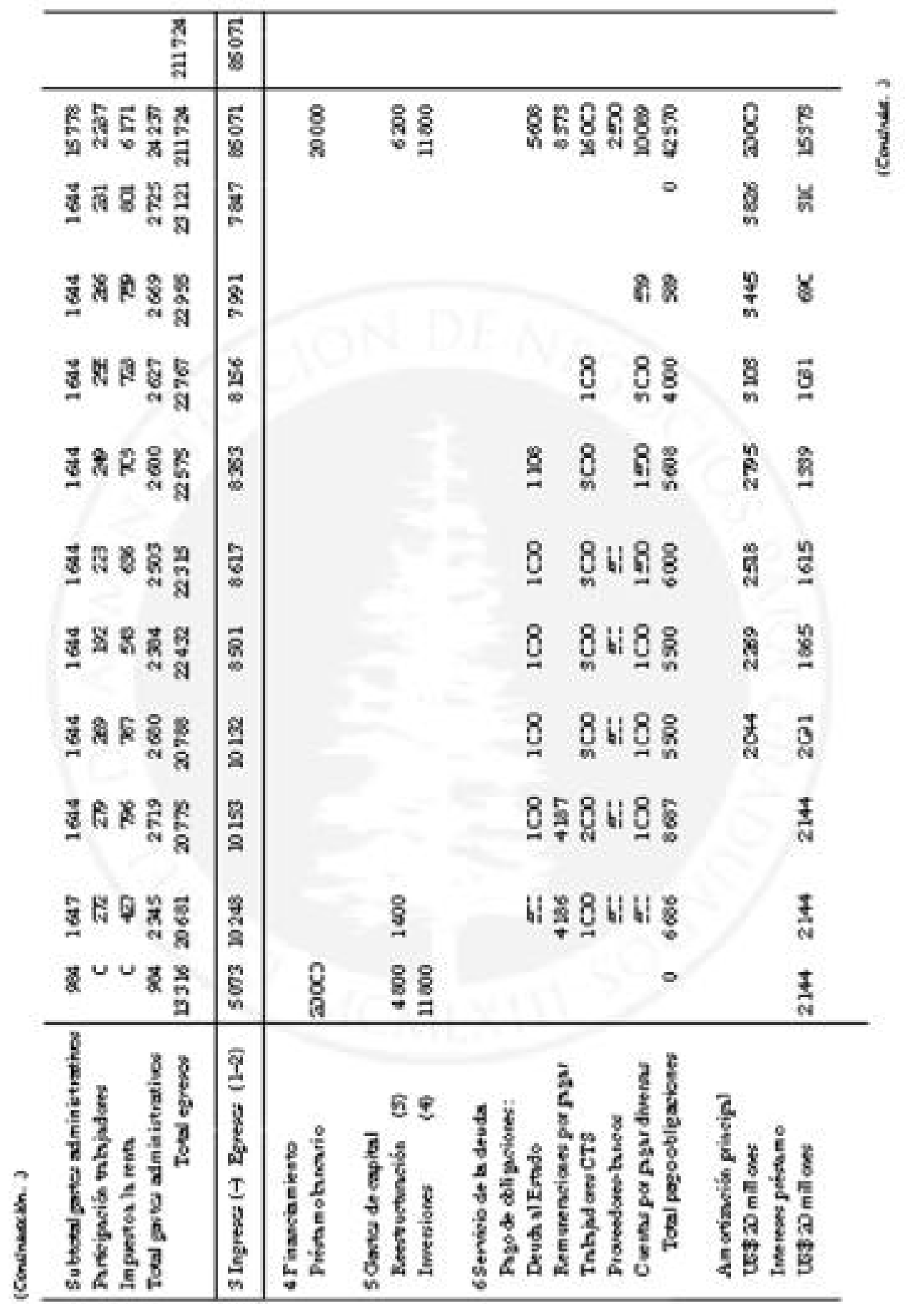




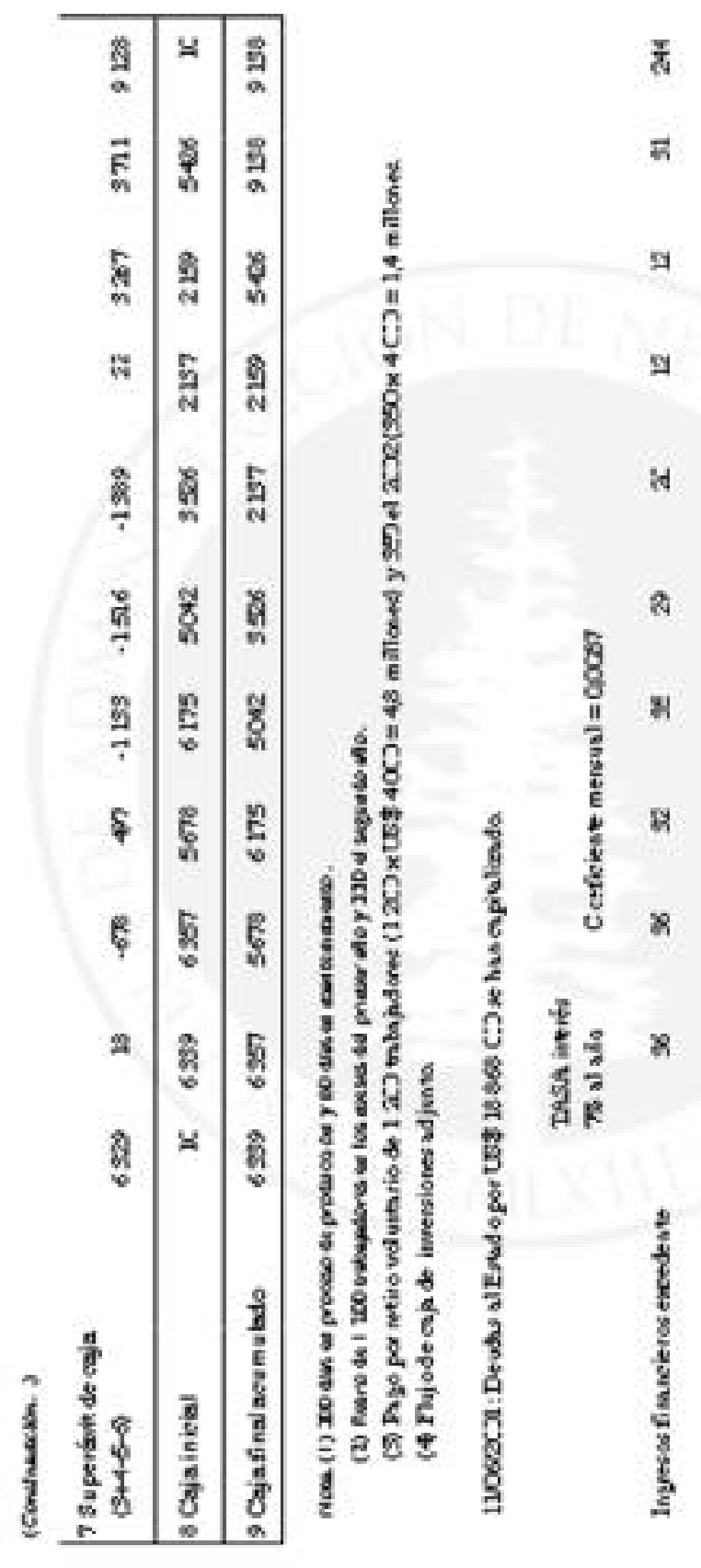




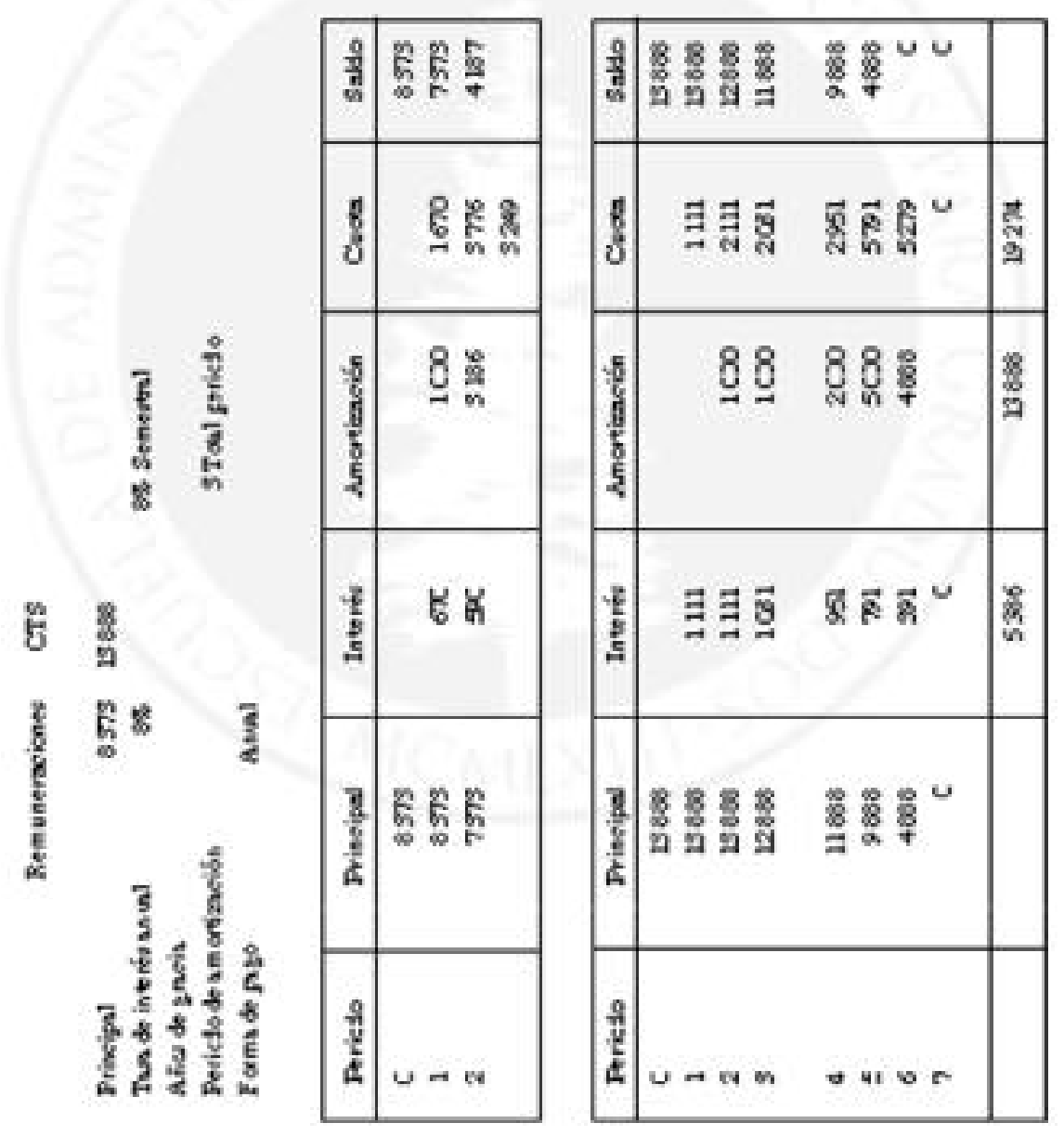




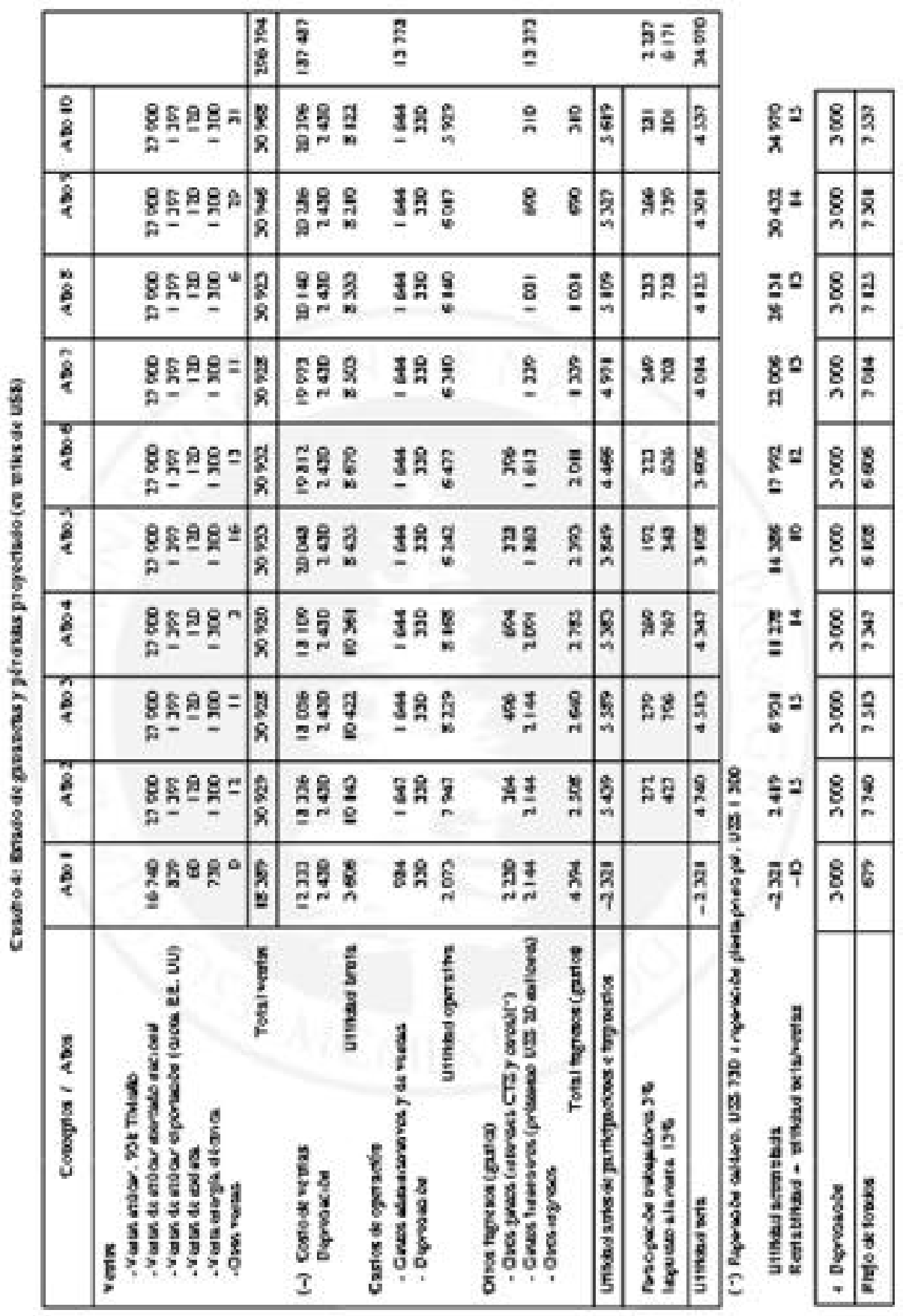




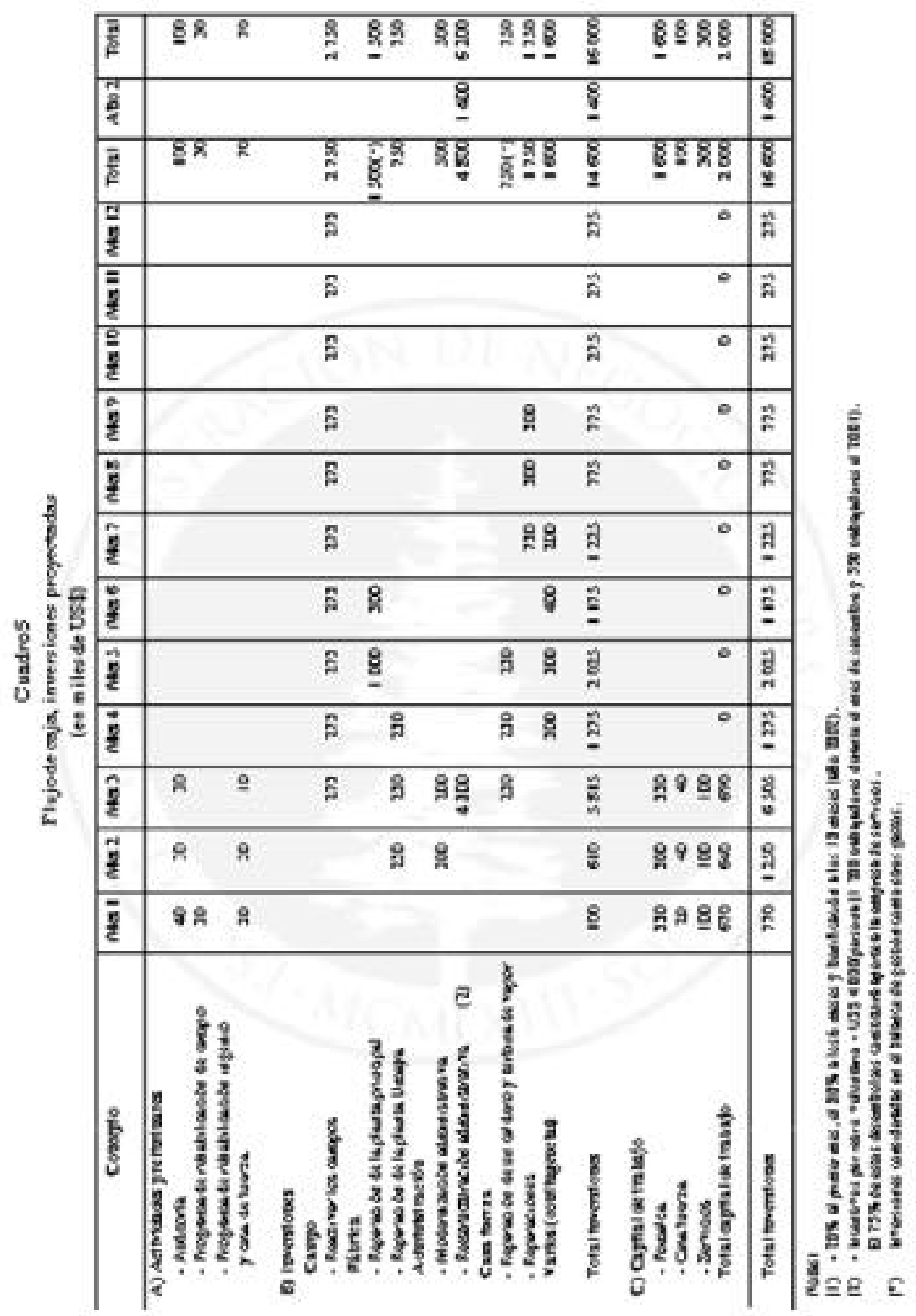




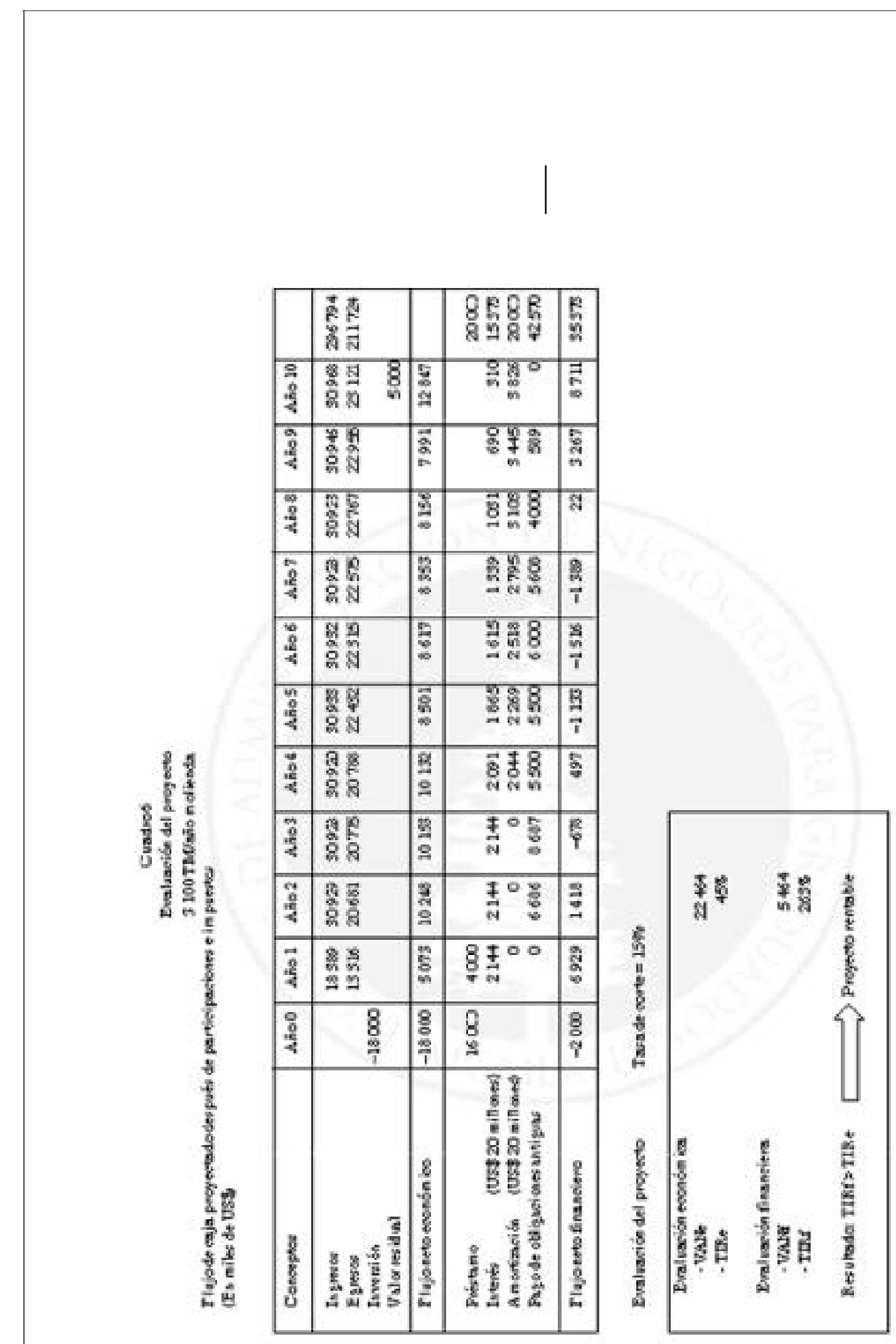


Cuadro 7

Servicio de la deuda

Principal:

US\$ 20 millones

Tasa de interés anual:

Años de gracia:

$11 \%$

$5,36 \%$ Semestral

Periodo de amortización:

tres (3)

Forma de pago:

diez (10) años

14 Total periodo semestral

\begin{tabular}{|c|c|c|c|c|c|}
\hline Periodo & Principal & Interés & Amortización & Cuota fija & Saldo \\
\hline 0 & 20000000 & & & & 20000000 \\
\hline 1 & 20000000 & 1072000 & & 1072000 & 20000000 \\
\hline 2 & 20000000 & 1072000 & & 1072000 & 20000000 \\
\hline 3 & 20000000 & 1072000 & & 1072000 & 20000000 \\
\hline 4 & 20000000 & 1072000 & & 1072000 & 20000000 \\
\hline 5 & 20000000 & 1072000 & & 1072000 & 20000000 \\
\hline 6 & 20000000 & 1072000 & & 1072000 & 20000000 \\
\hline 7 & 20000000 & 1072000 & 995251 & 2067251 & 19004749 \\
\hline 8 & 19004749 & 1018655 & 1048596 & 2067251 & 17956153 \\
\hline 9 & 17956153 & 962450 & 1104801 & 2067251 & 16851351 \\
\hline 10 & 16851351 & 903232 & 1164019 & 2067251 & 15687333 \\
\hline 11 & 15687333 & 840841 & 1226410 & 2067251 & 14460923 \\
\hline 12 & 14460923 & 775105 & 1292146 & 2067251 & 13168777 \\
\hline 13 & 13168777 & 705846 & 1361405 & 2067251 & 11807373 \\
\hline 14 & 11807373 & 632875 & 1434376 & 2067251 & 10372997 \\
\hline 15 & 10372997 & 555993 & 1511258 & 2067251 & 8861739 \\
\hline 16 & 8861739 & 474989 & 1592262 & 2067251 & 7269477 \\
\hline 17 & 7269477 & 389644 & 1677607 & 2067251 & 5591870 \\
\hline 18 & 5591870 & 299724 & 1767527 & 2067251 & 3824343 \\
\hline 19 & 3824343 & 204985 & 1862266 & 2067251 & 1962077 \\
\hline 20 & 1962077 & 105167 & 1962077 & 2067244 & 0 \\
\hline \multicolumn{2}{|c|}{ Totales } & 15373507 & 20000000 & $\begin{array}{r}35 \mathbf{3 7 3 5 0 7} \\
2067251\end{array}$ & \\
\hline
\end{tabular}




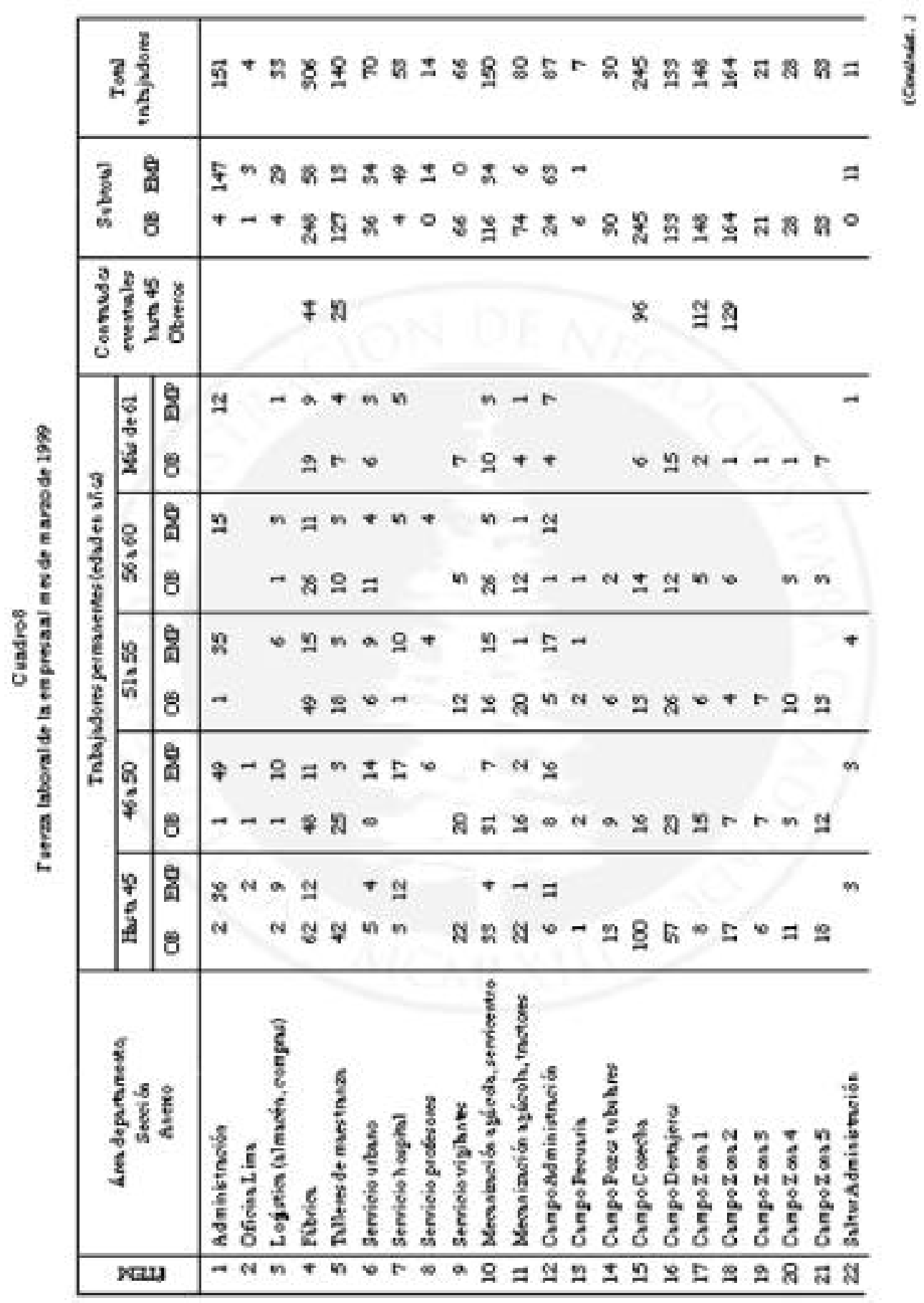




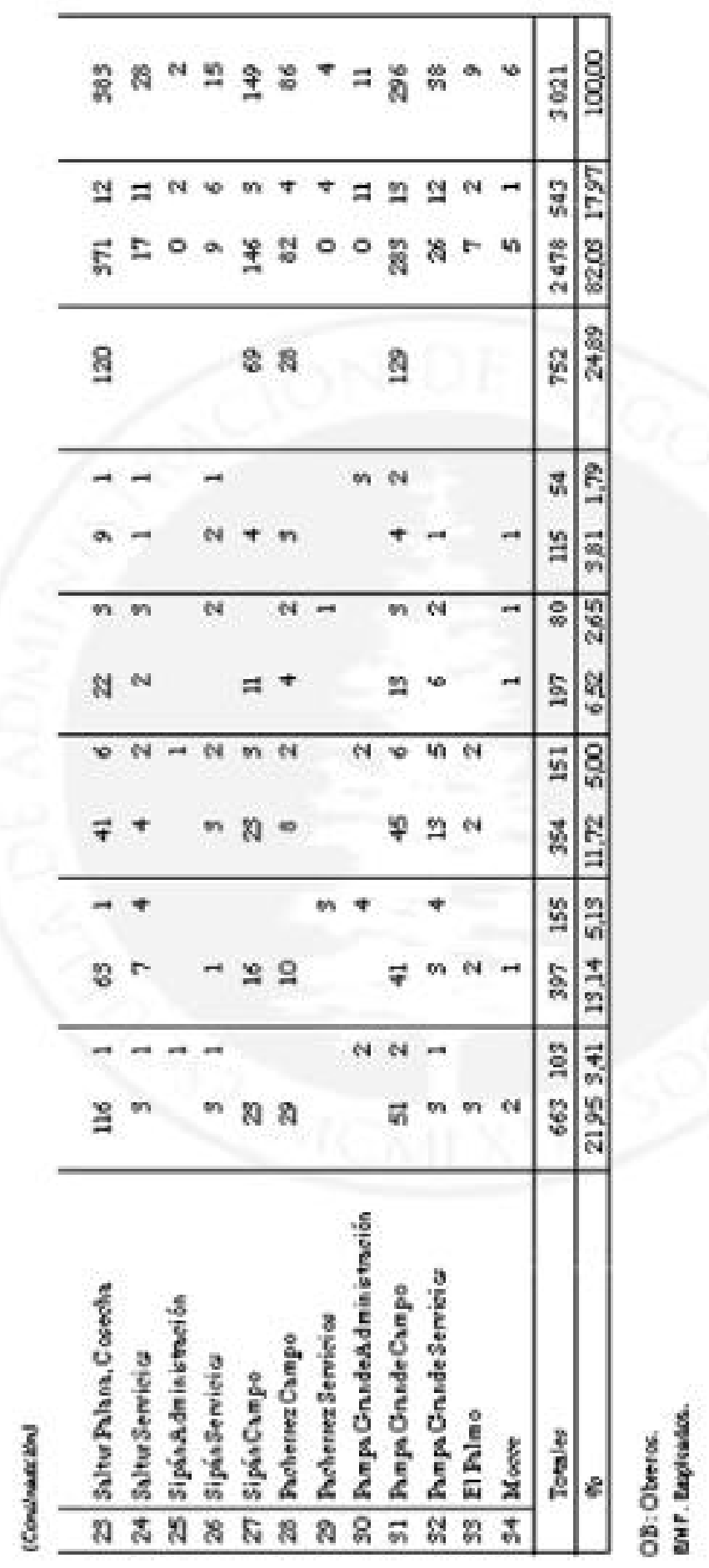

